\title{
ДЕФИЦИТ ВИТАМИНА D В РОССИЙСКОЙ ФЕДЕРАЦИИ: РЕЗУЛЬТАТЫ КРОСС-СЕКЦИОННОГО ИССЛЕДОВАНИЯ
}

\author{
'Суплотова Л.А., ' Авдеева В.А., ${ }^{2}$ Пигарова Е.А., ${ }^{2}$ Рожинская Л.Я., ${ }^{3}$ Каронова Т.Л., ${ }^{2}$ Трошина Е.А. \\ 'Тюменский государственный медицинский университет, Тюмень, Россия. \\ ${ }^{2}$ Национальный медицинский исследовательский чентр эндокринологии, Москва, Россия. \\ ${ }^{3}$ Национальный медицинский исследовательский чентр имени В.А. Алмазова, Санкт-Петербург, Россия
}

ЦЕЛЬ: оценить частоту дефицита и недостаточности витамина D у населения Российской Федерации в репрезентативной выборке регионов, расположенных в широтах от $45^{\circ}$ до $70^{\circ}$.

МАТЕРИАЛЫ И МЕТОДЫ: Российское многоцентровое неинтервенционное регистровое исследование по методу «поперечных срезов». Изучаемая популяция: 996 добровольцев из 10 регионов Российской Федерации (г. Москва, Ростов-на-Дону, Санкт-Петербург, Мурманск, Екатеринбург, Тюмень, Кызыл, Владивосток, Норильск, Новосибирск). Исследовательскую группу составили здоровые добровольцы, подписавшие информированное согласие на участие в исследовании. Исследование проведено в два периода - с марта по май (весна) и с октября по ноябрь (осень) 2020 г. Уровень 25(OH)D расценивался как достаточный при концентрации 25(OH)D $\geq 30$ нг/мл ( $\geq 75$ нмоль/л), недостаточный $-\geq 20$ и $<30$ нг/мл ( $\geq 50$ и $<75$ нмоль/л), дефицит —<20 нг/мл ( $<50$ нмоль/л). Уровень 25(OH)D определяли в сыворотке крови методом хемилюминесцентного иммуноанализа. Набор и анкетирование участников исследования проводились на базе медицинских офисов компании ООО «ИНВИТРО». Исследование выполнено при финансовом обеспечении компании АО «АКРИХИН» № AQ-01/20, версия 2.0 от 25 февраля 2020.

РЕзУЛЬТАТЫ: в исследовании проведена оценка уровня 25(OH)D в различных географических регионах РФ. Согласно результатам проведенного исследования дефицит витамина D зарегистрирован в 39,4\% случаев, недостаточность в 32,8\%. Суммарно у 72,2\% обследованных выявлен дефицит или недостаточность витамина $D$, а его оптимальный уровень диагностирован в 27,8\%. При сравнении данных за первый (весна) и второй (осень) периоды были выявлены существенные статистически значимые различия ( $<<0,00001$, критерия $X^{2}$ Пирсона) между периодами: недостаточность или дефицит витамина $D$ наблюдался у $84,3 \%$ участников весной и у $62,4 \%$ участников осенью. Также в исследовании были изучены базовые демографические характеристики, такие как пол и возраст. Полученные данные свидетельствуют, что наибольшая встречаемость дефицита и недостаточности витамина D зафиксирована у лиц мужского пола, в сравнении с женщинами ( $p=0,013,79,1 \%$ и 70,4\% соответственно), а дефицит витамина $D$ наблюдался у молодых людей в возрастной подгруппе 18-25 лет ( $<<0,001,54,0 \%$ в целом по исследованию) значительно чаще по сравнению с лицами более старшего возраста.

Выводы: результаты проведенного исследования указывают на повсеместную значительную распространенность дефицита и недостаточности витамина D в PФ, вне зависимости от региона проживания и времени года. Также, в рамках данного анализа основную группу риска по низкому уровню 25(OH)D coставили мужчины молодого возраста.

КЛЮЧЕВЫЕ СЛОВА: витамин D; дефицит и недостаточность 25(ОН)D; распространенность; эпидемиология. 